\title{
MAPPING INDUCED POLARIZATION WITH NATURAL ELECTROMAGNETIC FIELDS FOR EXPLORATION AND RESOURCES CHARACTERIZATION BY THE MINING INDUSTRY
}

Quarterly Technical Progress Report

Reporting Period Start Date: 1/1/02

Reporting Period End Date: 3/31/02

Principal Author: Edward Nichols

Report Date: May 3, 2002

DOE Award number

DE-FC26-01NT41060

Electromagnetic Instruments, Inc.

1301 S. $46^{\text {th }}$ St, UCRFS Bldg. 300

Richmond, CA 94804 
This report was prepared as an account of work sponsored by an agency of the United States Government. Neither the United States Government nor any agency thereof, nor any of their employees, makes any warranty, expressed or implied, or assumes any legal liability or responsibility for the accuracy, completeness, or usefulness of any information, apparatus, product, or process disclosed, or represents that its use would not infringe privately owned rights. Reference herein to any specific commercial product, process, or service by trade name, trademark, manufacturer, or otherwise does not necessarily constitute or imply its endorsement, recommendation, or favoring by the United States Government or any agency thereof. The views and opinions of authors expressed herein do not necessarily state or reflect those of the United States Government or any agency thereof. 


\begin{abstract}
In this quarter we continued the processing of the Safford IP survey data. The processing identified a time shift problem between the sites that was caused by a GPS firmware error. A software procedure was developed to identify and correct the shift, and this was applied to the data. Preliminary estimates were made of the remote referenced MT parameters, and initial data quality assessment showed the data quality was good for most of the line. The multi-site robust processing code of Egbert was linked to the new data and processing initiated.
\end{abstract}




\section{Table of Contents}

1. Objective

2. Project description

3. Summary of Progress

3.1 Manufacturing of seven MT24/LF systems

3.2 Survey in Safford Arizona

3.3 Data Processing 


\section{Mapping induced polarization with natural electromagnetic fields for exploration and resources characterization by the mining industry}

\section{Objective}

The objective of this project is to demonstrate the use of a new geophysical system to collect economically competitive induced polarization (IP) data using natural electromagnetic (EM) fields as a source.

The natural EM fields are an attractive source since these can eliminate many of the logistics related to deploying and operating a conventional IP transmitter. The strong low frequency energy available in this source provides greater depth of exploration and hence provides significant economic, energy, environmental and safety benefits.

\section{Project Description}

The purpose of this project is to use a new geophysical field system, designed to efficiently collect EM data along a profile line, to obtain IP data using natural EM fields as the source. The technique is non-invasive, eliminates the need for current electrodes and motor generator sets and provides greater depth of exploration than controlled-source IP surveys. During the course of the project, we will complete the adaptation of a new field system for natural IP data collection, determine the procedures for its efficient deployment and demonstrate the usefulness of natural IP.

\section{Summary of Progress}

In this quarter, the data processing for the final field survey in Arizona was undertaken. A problem with non-synchronized start of acquisition was found for several of the systems. This problem was traced back to a firmware error related to the use of a new GPS receiver used for some of the sites. The impact of this timing error is that the software needed to be developed to quantify the amount of startup shift and then eliminate it from the problem sites. This processing occupied most of this quarter. The effect of the synchronization error is troublesome since all of the sites needed to be timereferenced to a separate site having the magnetic reference fields for the survey in order to recover the IP effects. 


\subsection{Survey in Safford, Arizona}

NFIP survey on Sol deposit in Safford, Arizona was done in October 2001. The profile was $6.2 \mathrm{~km}$ long, and we acquired measurements every $200 \mathrm{~m}$. The location of the profile is shown in Figure 1.

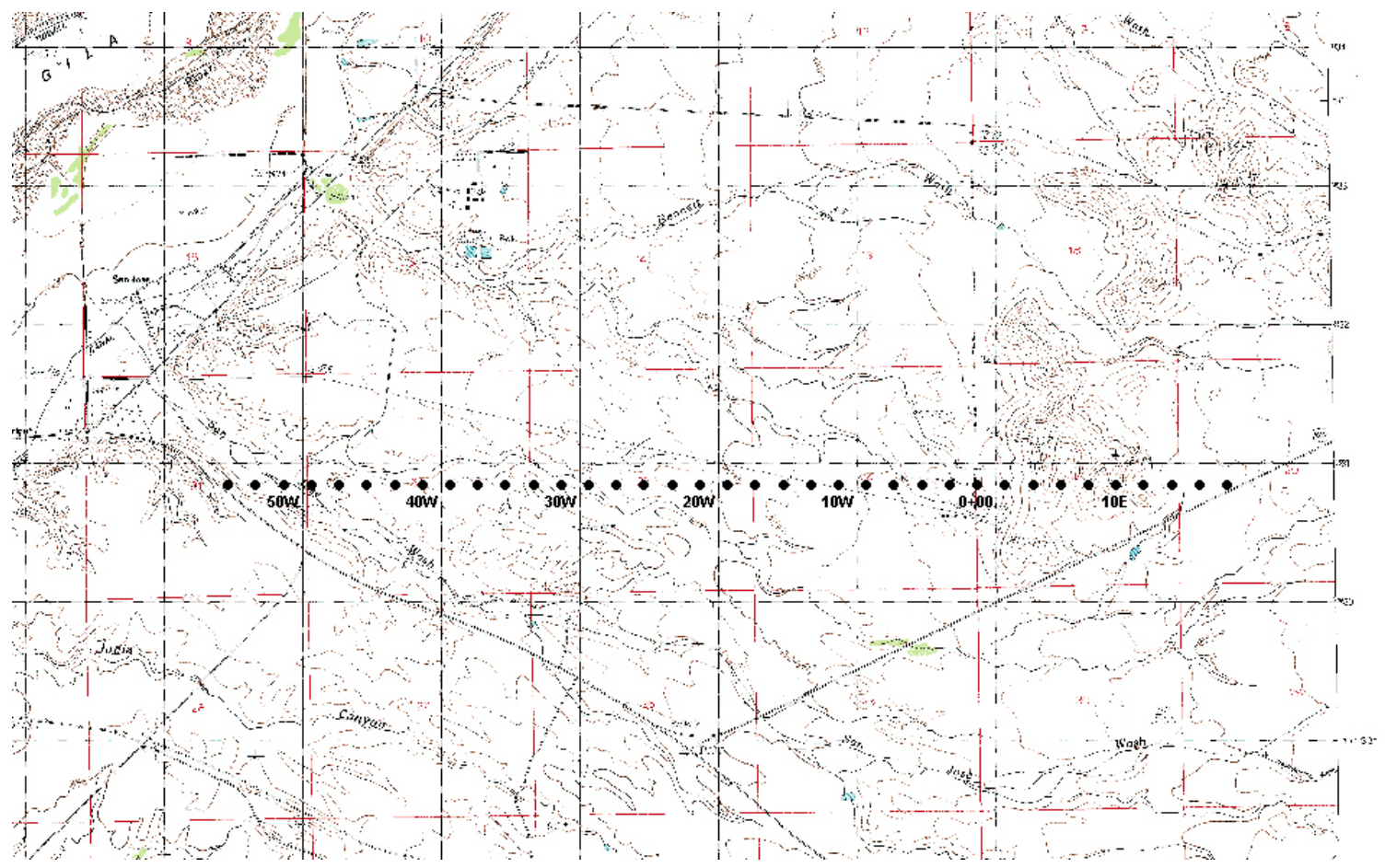

Figure 1

Field setup consisted of two remote stations with orthogonal electric and magnetic sensors, and data along the profile were measured with L-shape configuration, two electric dipoles along the profile and one electric dipole perpendicular to the line. The field setup is shown in Figure 2.

Remote Site 2

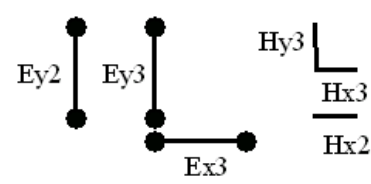

Remote site 1

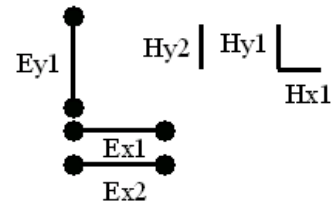

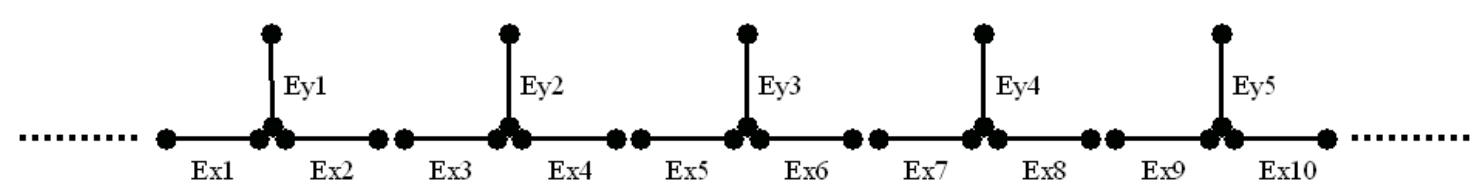

Figure 2 
The field survey was done between October 9, 2001 and October 15, 2001. The measured profile was along the line from an IP survey in 1975. The schematic geological cross-section along this profile is shown in Figure 3.

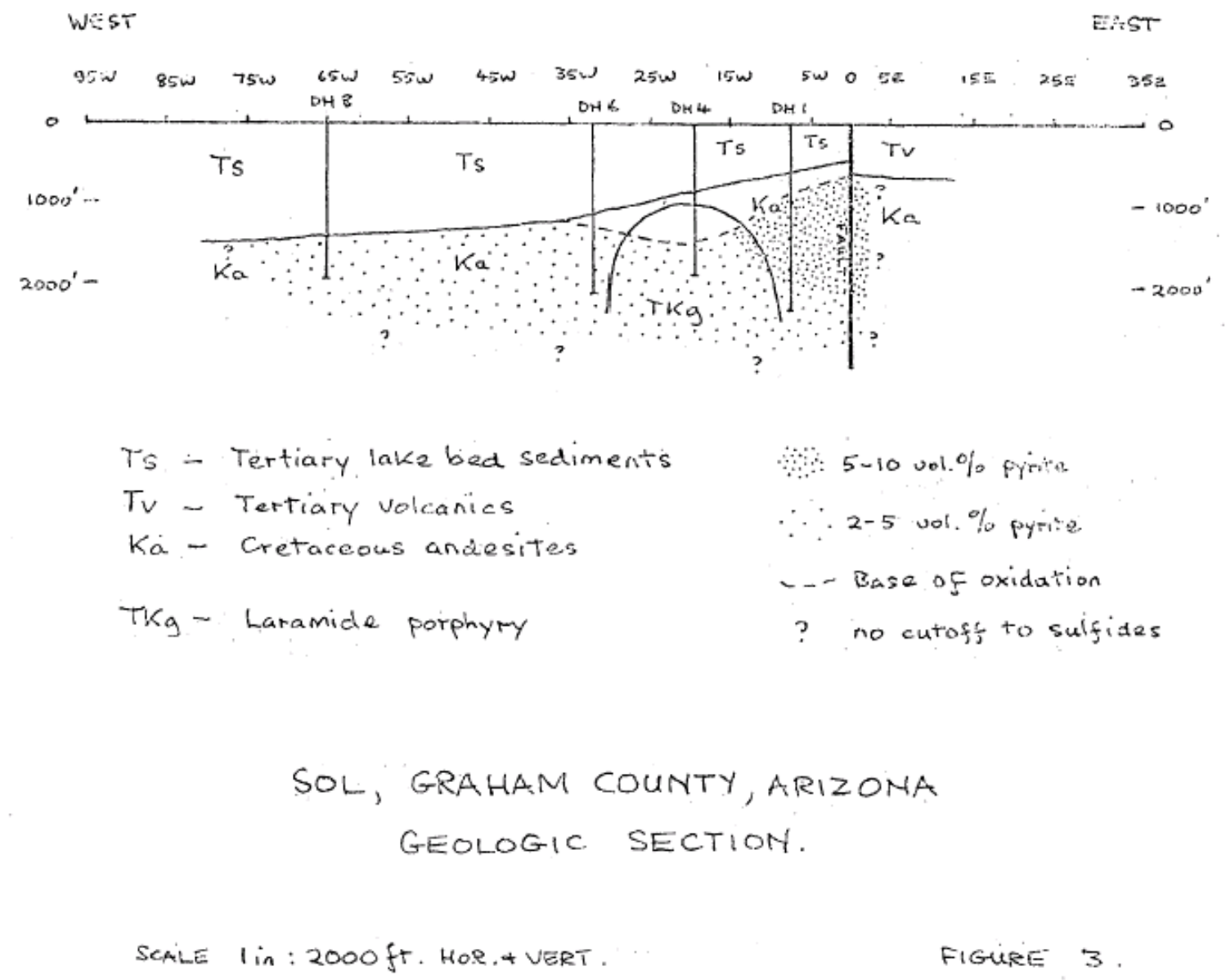

In general, we recorded data for at least 20 hours. Most of the time we had 4 systems acquiring data simultaneously; one day we had 5 systems running simultaneously, and one day all 7 systems.

\subsection{Time Shift Identification}

Due to a Firmware problem, there was a timing error between various systems. Time shifts (in samples) are given in Table 1. 


$\begin{array}{cc}\text { Arizona 2001 } & \\ \text { Date } & \text { System 1 } \\ 281 & 111 \\ 281 & 111 \\ 281 & 111 \\ 281 & 111 \\ 281 & 111 \\ 281 & 111 \\ 281 & 111 \\ 281 & 111 \\ 281 & 111 \\ 281 & 111 \\ 281 & 111 \\ 281 & 111\end{array}$

System shifts

Shift (samples)

63

5000

500

56

4500

450

56

4500

450

56

4500

450

$\begin{array}{cc}\text { System } 2 & \text { Parallel test } \\ 112 & \text { Band } \\ 112 & \text { LF } \\ 112 & \text { J } \\ 113 & \text { N } \\ 113 & \text { LF } \\ 113 & \text { J } \\ 114 & \text { LF } \\ 114 & \text { J } \\ 114 & \text { N } \\ 117 & \text { LF } \\ 117 & \text { J } \\ 117 & \text { N }\end{array}$

Table 1

This time shift influences calculations, and it is evident in the plot of Transfer Phase between various Ex dipoles. Illustration of this is given in Figure 4. Figure 4a shows the transfer phase between two Ex components recorded with the same system, in this case system $24 \mathrm{LF}-115$, Figure $4 \mathrm{~b}$ shows the transfer phase between Ex dipoles from system 24LF-1 15 and 116, and Figure 4c shows the transfer phase between Ex dipoles from system 24LF-115 and 112.

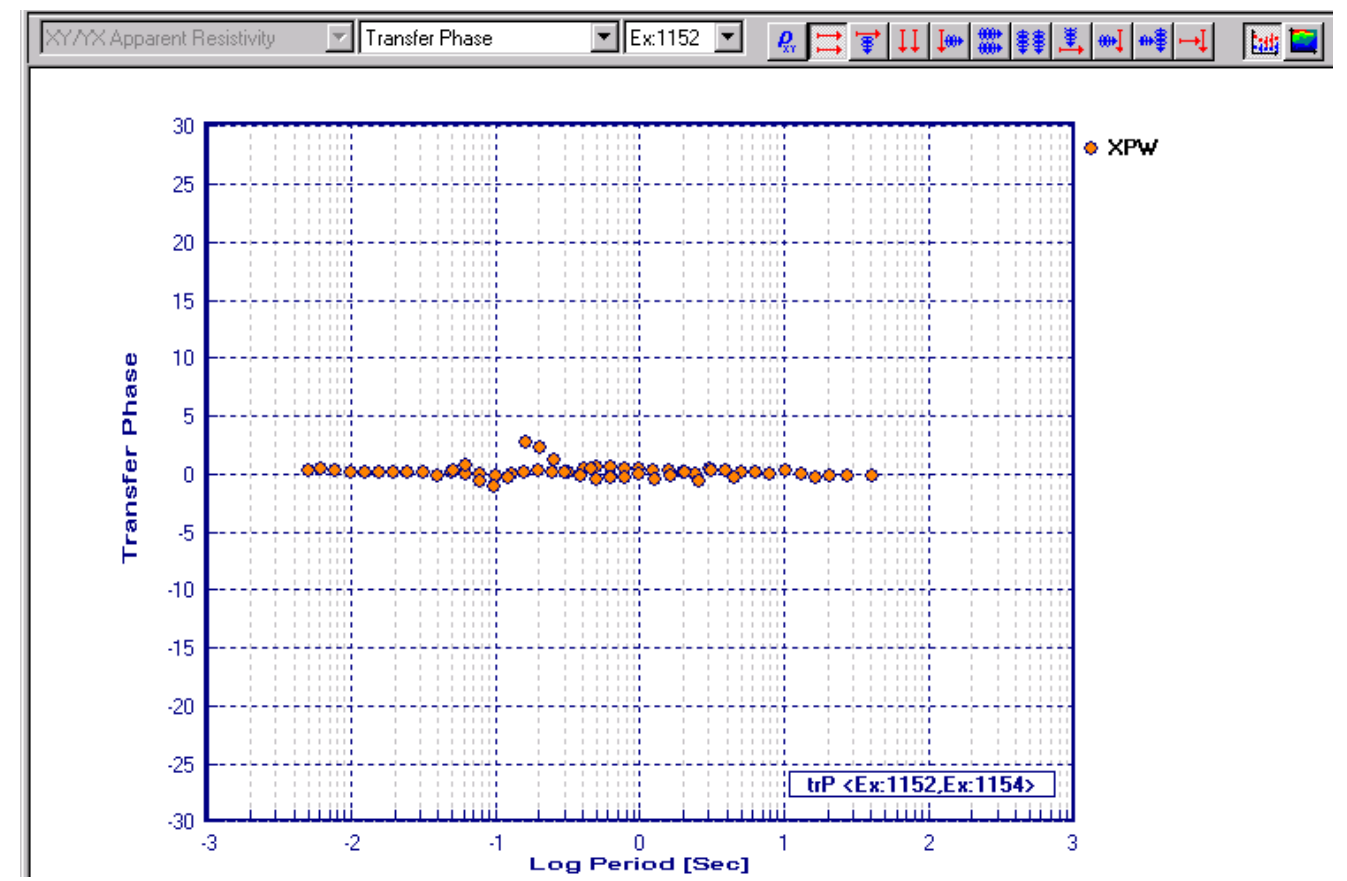

Figure $4 \mathrm{a}$ 


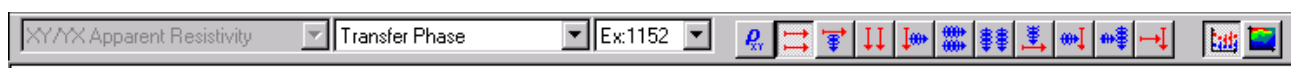

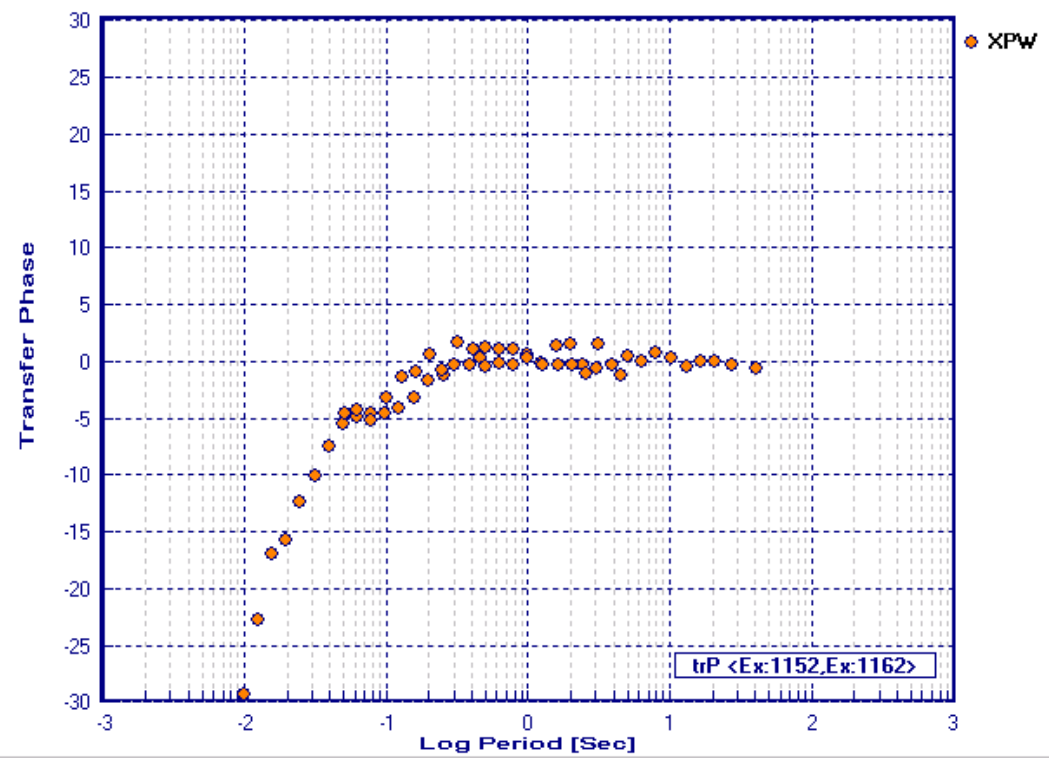

Figure $4 b$

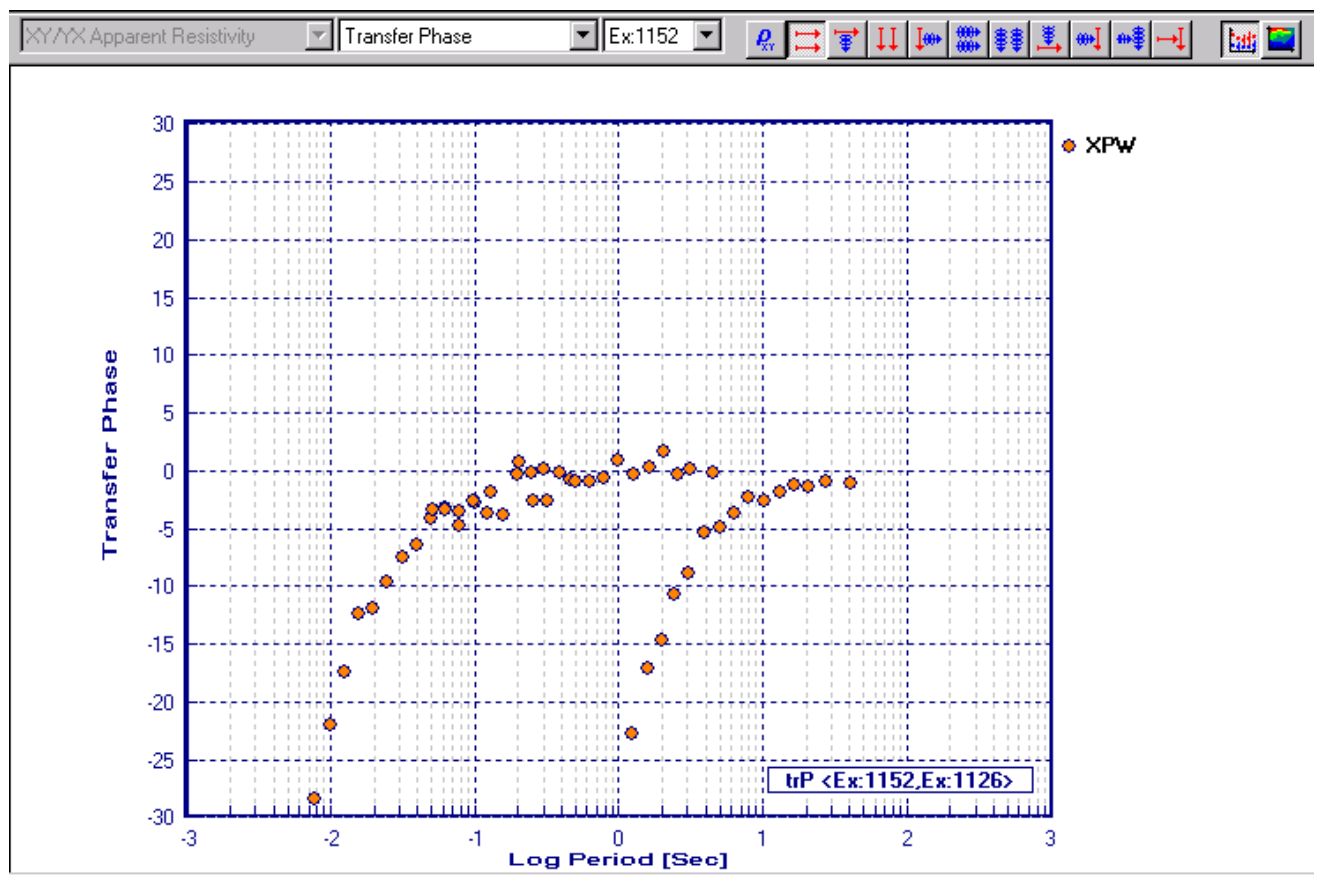

Figure 4c 


\subsection{MT Parameter Data Processing}

We have started processing of all data both with EMI's cross-power calculation program and Egbert's multi-station robust processing program. We expect to complete data processing in May 2002 and complete final interpretation by June 2002. Figures 5 and 6 show xy-mode cross-sections of resistivity and phase, respectively, along the profile (using data calculated using cross-powers).

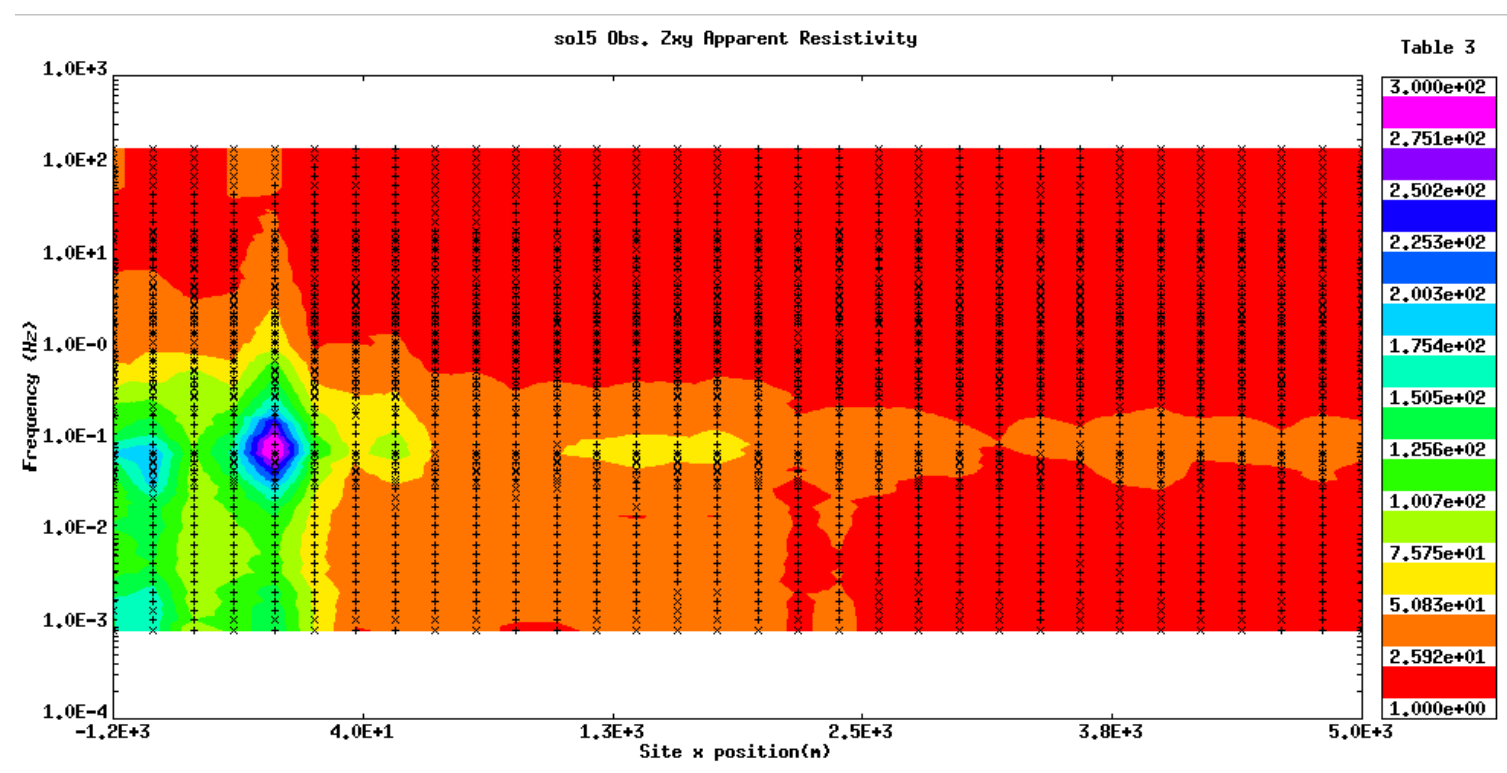

Figure 5

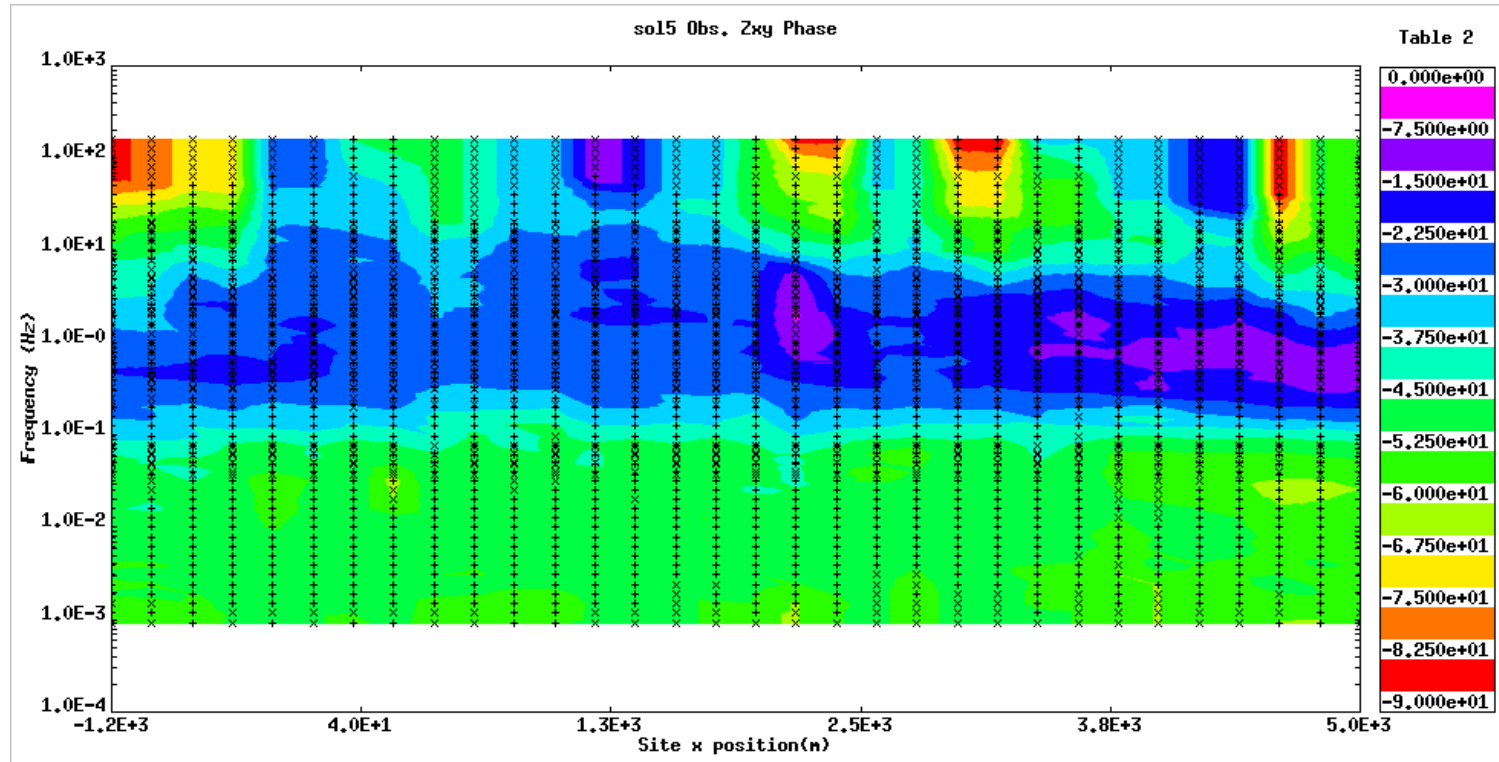

Figure 6 